\title{
Combination of a third generation bisphosphonate and replication-competent adenoviruses augments the cytotoxicity on mesothelioma
}

Yuanyuan Jiang ${ }^{1,2}$, Boya Zhong ${ }^{1,2}$, Kiyoko Kawamura', Takao Morinaga ${ }^{1}$, Masato Shingyoji ${ }^{3}$, Ikuo Sekine ${ }^{4}$, Yuji Tada ${ }^{5}$, Koichiro Tatsumi ${ }^{5}$, Hideaki Shimada ${ }^{6}$, Kenzo Hiroshima ${ }^{7}$ and Masatoshi Tagawa ${ }^{1,2^{*}}$

\begin{abstract}
Background: Approximately $80 \%$ of mesothelioma specimens have the wild-type $p 53$ gene, whereas they contain homozygous deletions in the INK4A/ARF locus that encodes $p 14^{A R F}$ and the $16^{I N K 4 A}$ genes. Consequently, the majority of mesothelioma is defective of the p53 pathways. We examined whether zoledronic acid (ZOL), a third generation bisphosphonate, and adenoviruses with a deletion of the E1B-55kD gene (Ad-delE1B55), which augments p53 levels in the infected tumors, could produce combinatory anti-tumor effects on human mesothelioma cells bearing the wild-type $p 53$ gene.

Methods: Cytotoxicity of ZOL and Ad-delE1B55 was assessed with a WST assay. Cell cycle changes were tested with flow cytometry. Expression levels of relevant molecules were examined with western blot analysis to investigate a possible mechanism of cytotoxicity. Furthermore, the expressions of Ad receptors on target cells and infectivity were estimated with flow cytometry. Viral replication was assayed with the tissue culture infection dose method.

Results: A combinatory use of ZOL and Ad-delE1B55 suppressed cell growth and increased sub-G1 or S-phase populations compared with a single agent, depending on cells tested. The combinatory treatment up-regulated p53 levels and subsequently enhanced the cleavage of caspase-3, 8, 9 and poly (ADP-ribose) polymerase, but expression of molecules involved in autophagy pathways were inconsistent. ZOL-treated cells also increased Ad infectivity with a dose-dependent manner and augmented Ad replication although the expression levels of integrin molecules, one of the Ad receptors, were down-regulated.

Conclusions: These findings indicated that ZOL and Ad-delE1B55 achieved combinatory anti-tumor effects through augmented apoptotic pathways or increased viral replication.
\end{abstract}

Keywords: Mesothelioma, Replication-competent adenovirus, Bisphosphonates, p53

\section{Background}

Malignant pleural mesothelioma, developed in the pleural cavity, is often associated with asbestos exposure in the patient history $[1,2]$. The prognosis remains poor and mesothelioma is resistant to a number of chemotherapeutic and molecular-targeting agents. A novel

\footnotetext{
* Correspondence: mtagawa@chiba-cc.jp

${ }^{1}$ Division of Pathology and Cell Therapy, Chiba Cancer Center Research

Institute, 666-2 Nitona, Chuo-ku, Chiba 260-8717, Japan

2Department of Molecular Biology and Oncology, Graduate School of

Medicine, Chiba University, Chiba, Japan

Full list of author information is available at the end of the article
}

therapeutic strategy is thereby required to improve the prognosis. Mesothelioma has a characteristic genetic change. Previous analyses showed that approximately $80 \%$ of mesothelioma specimens had a homozygous deletion in the INK4A/ARF locus which encoded $p 14^{A R F}$ and the $16^{I N K 4 A}$ genes, but the $p 53$ genotype was infrequently mutated $[3,4]$. The genetic defect leads to inactivation of the p53 pathways and may be linked with decreased susceptibility to anti-cancer agents.

Bisphosphonates are synthetic analogues of pyrophosphates and show high binding affinity to mineralized 
bone matrix [5]. Previous reports showed that bisphosphonates produced cytotoxic effects on tumors such as breast and prostate cancer $[6,7]$, and these cytotoxic actions were attributable to a number of mechanisms including apoptosis induction and anti-angiogenesis [5, 8]. Zoledronic acid (ZOL), one of the third generation of bisphosphonates, inhibits the farnesyl pyrophosphate synthetase, a key enzyme in the mevalonate pathway, and depletes isoprenoid pools, which subsequently results in decreased prenylation of small guanine-nucleotide-binding regulatory proteins (small G proteins) [5]. Consequently, ZOL prevented growth, adhesion or spreading, and invasion of cancer cells [5, 9]. In our previous study, we demonstrated ZOL-mediated cytotoxic effects on mesothelioma cells [10] and showed that ZOL treatments improved cytotoxicity of adenoviruses (Ad) expressing the p53 gene on mesothelioma [11]. Further analyses indicated that augmentation of $\mathrm{p} 53$ by ZOL was essential in combinatory effects of ZOL and DNA damaging drugs which included the first-line anti-cancer agents for mesothelioma [11].

Replicating-competent Ad is a new strategy for cancer therapy. They can spread and destroy tumors without deleterious effects in normal tissues $[12,13]$. The replicable Ad continuously release the progenies from infected tumors and consequently circumvent low transduction efficacy. This replicable propensity enhances the cytotoxicity but host immunity can be inhibitory to the viral spreading. Ad lacking the E1B-55 kDa molecules (Ad-delE1B55) are replication-competent and were originally hypothesized to target only p53-mutated or -null tumors due to the defect in p53-inactivating E1B-55 kDa protein [14]. Nevertheless, Ad proteins that are synthesized during the replication also regulate p53 expression in infected cells at various levels even in an epigenetic manner [15]. Subsequent studies in fact showed that Ad-delE1B55-induced cytotoxicity was not always related to the $p 53$ genotype [16]. Moreover, our previous study showed that Ad-delE1B55 produced cytotoxicity on mesothelioma cells with the wild-type $p 53$ gene and achieved combinatory anti-tumor agents with the first-line chemotherapeutic agents [17].

In the present study, we examined whether ZOL and AddelE1B55 could produce combinatory anti-tumor effects on human mesothelioma cells carrying the wild-type $p 53$ gene. We speculated that both agents augmented endogenous p53 levels, which resulted in augmentation of the cytotoxicity. Furthermore, we analyzed a possible mechanism of the combination and investigated involvement of apoptotic pathways and viral replication in the anti-tumor effects.

\section{Methods}

\section{Cells}

Human mesothelioma cells, MSTO-211H, NCI-H28, NCI-H226, NCI-H2452 cells, all of which were purchased from American Type Culture Collection (Manassas, VA,
USA), and EHMES-10 (provided from Dr. Hironobu Hamada, Hiroshima University, Japan) [18] and were cultured with RPMI 1640 medium with $10 \%$ fetal calf serum. HEK 293 and A549 cells, derived from American Type Culture Collection and Dr. Katsuyuki Hamada (Ehime University), respectively, were cultured with in Dulbecco's Modified Eagle's Medium containing 10 \% fetal calf serum. NCI-H28, NCI-H2452 and EHMES-10 cells are defective of the $p 14^{A R F}$ and $p 16^{I N K 4 A}$ genes, and MSTO- $211 \mathrm{H}$ and NCI-H226 cells lack the $p 14$ and $p 16$ transcription (Additional file 1: Figure S1). Sequence analyses showed that all of them possessed the wild-type $p 53$ gene.

\section{Ad preparation}

Replication-competent Ad-delE1B55 (Accession number for Ad; M73260), in which the $55 \mathrm{kDa}$ molecule-encoding E1B region (corresponding to 2019-3509 in M73260 sequences) is deleted, and replication-incompetent Ad expressing the $\beta$-galactosidase (NM066611) (Ad-LacZ) or the green fluorescent protein gene (U55762) (Ad-GFP) powered by the cytomegalovirus promoter (KU317610), were prepared with an Adeno-X expression system (Takara, Shiga, Japan) and HEK293 cells. The numbers of virus particles (vp) per ml was estimated with the formula [absorbance at $260 \mathrm{~nm}$ of purified Ad in the presence of $0.1 \%$ sodium dodecyl sulfate].

\section{Cell cycle analysis and Giemsa staining}

Cells treated with ZOL (Novartis, Basel, Switzerland) and/ or either Ad-delE1B55 or Ad-LacZ as a control were fixed in ice-cold $100 \%$ ethanol, incubated with RNase $(50 \mu \mathrm{g} /$ $\mathrm{ml})$ and stained with propidium iodide $(50 \mu \mathrm{g} / \mathrm{ml})$. The staining profiles were analyzed with FACSCalibur and CellQuest software (BD Biosciences, CA, USA). We set up a gated area for data collection to remove doublets signals (Additional file 2: Figure S2). For Giemsa staining, cells treated with ZOL and/or Ad-delE1B55 were treated with colcemid $(10 \mu \mathrm{g} / \mathrm{ml})$. They were further incubated with hypotonic buffer and stained with Giemsa solution.

\section{Viability test in vitro}

Cells $\left(5 \times 10^{3} /\right.$ well) in 96 -well plates were cultured with ZOL and/or Ad-delE1B55 for 5 days. Cell viability was determined with a cell-counting WST kit (Wako, Osaka, Japan) and the relative viability was calculated based on the absorbance without any treatments. Viable cell numbers were also counted with the trypan blue dye exclusion test. Combinatory effects were examined with CalcuSyn software (Biosoft, Cambridge, UK). Combination index (CI) values at respective fractions affected (Fa) points, which showed relative suppression levels of the cell viability, were calculated based on the WST assay. CI $<1, \mathrm{CI}=1$ and $\mathrm{CI}>1$ indicate synergistic, additive and antagonistic actions, respectively. 


\section{Western blot analysis}

Cells were cultured with ZOL and/or either Ad-delE1B55 or Ad-LacZ, and the cell lysate was subjected to sodium dodecyl sulfate polyacrylamide gel electrophoresis. The protein was transferred to a nylon filter and was hybridized with antibodies $(\mathrm{Ab})$, against p53 (Thermo Fisher Scientific, Fremont, CA, USA), phosphorylated p53 at serine (Ser) 15, Bid (detecting truncated-Bid as well), caspase-3, cleaved caspase-3, caspase-8, cleaved caspase-8, caspase-9, cleaved caspase-9, poly (ADP-ribose) polymerase (PARP), Beclin-1, Atg5, LC3A/B (Cell Signaling, Danvers, MA, USA), cyclin A, cyclin E, type 2/5 Ad E1A (Santa Cruz Biotech, Dallas, TX, USA), phosphorylated H2 histone family member (H2AX) at Ser 139 (Biolegend, San Diego, CA, USA), hexon (Abcam, Cambridge, UK) and $\alpha$-Tubulin (Thermo Fisher Scientific) as a loading control. The membranes were developed with the ECL system (GE Healthcare, Buckinghamshire, UK).

\section{Infectivity with Ad-GFP and expression of Ad receptors} Cells were infected with Ad-GFP at several vp doses for $30 \mathrm{~min}$ and were then washed to remove Ad. Infected cells were cultured for $48 \mathrm{~h}$ and then analyzed for percentages of GFP-positive cells with FACSCalibur and CellQuest software. Cells of which fluorescence was greater than the brightest $5 \%$ of uninfected cells were judged as positively stained. For detecting Ad receptors, cells were stained with anti-coxsackie adenovirus receptors (CAR) (Upstate, Charlottesville, VA, USA), integrin $\alpha v \beta 3$ (Chemicon, Billerica, MA, USA), integrin $\alpha v \beta 5$ (Abcam) $\mathrm{Ab}$ and the fluorescence intensity was analyzed with FACSCalibur and CellQuest software.

\section{Virus production}

Cells infected with Ad-delE1B55 were treated with or without ZOL. The cell lysates were examined for the cytotoxicity with A549 cells and the virus titers were calculated with the median tissue culture infectious dose $\left(\mathrm{TCID}_{50}\right)$ method.

\section{Results}

\section{Cytotoxic activities of ZOL and Ad-delE1B55 on} mesothelioma

We investigated possible cytotoxic effects produced by ZOL or Ad-delE1B55 on 5 kinds of mesothelioma, MSTO-211H, NCI-H226, NCI-H28, EHMES-10 and NCI-H2452 cells, which are defective of the $p 14^{A R F}$ and $p 16^{I N K 4 A}$ genes or the transcription but possess the wildtype $p 53$. Cells treated with ZOL showed decreased viability with a similar level (Fig. 1a), whereas the sensitivity to Ad-delE1B55 was different among the cells and EHMES-10 cells were resistant (Fig. 1b). Moreover, a separate experiment and a previous study showed that p53 of NCI-H2452 cells was truncated [19]. We therefore focused on MSTO-211H, NCI-H226 and NCIH28 cells for further analyses, which were sensitive to both agents.

We next examined cytotoxicity produced by a combinatory use of ZOL and Ad-delE1B55 (Fig. 2a). The combination achieved cytotoxicity greater than a single treatment. We examined the combinatory effects with the CalcuSyn software and showed that CI values were below 1 at most of the Fa points tested (between 0.3 and 0.8 in MSTO-211H and NCI-H226 cells and between 0.4 and 0.9 in NCI-H28 cells). These data indicated that the combination of ZOL and Ad-delE1B55 achieved additive or synergistic cytotoxicity in most of the cases. We noticed that NCI-H226 and NCI-H28 but not MSTO-211H cells were relatively resistant to ZOLmediated cell death assayed with the dye exclusion test although these cells were similarly sensitive to ZOL in the WST assay. The discrepancy was derived from differential measuring systems between the WST assay, detecting production of mitochondria-derived energy, and the dye exclusion test, detecting membrane permeability. We then treated NCI-H226 and NCI-H28 cells with relatively high ZOL concentrations $(60-100 \mu \mathrm{M})$ to induce the growth inhibition and cell death in the following experiments. In contrast, the high ZOL concentrations completely killed MSTO- $211 \mathrm{H}$ cells and we treated the cells at $10 \mu \mathrm{M}$. We then examined live cell numbers assayed with the dye exclusion test (Fig. 2b). Cell growth was gradually retarded and declined depending on the agents and cells, and the growth inhibition was stronger in the combination than in cells treated with ZOL or Ad-delE1B55 alone. Replicationincompetent Ad-LacZ as a control minimally suppressed the proliferation and did not produce combinatory effects with ZOL. These data collectively indicated that ZOL and Ad-delE1B55 achieved combinatory antitumor effects on mesothelioma.

\section{Cell cycle changes induced by ZOL and Ad-delE1B55}

We examined cell cycle changes in MSTO-211H and NCI-H28 cells with flow cytometry (Fig. 3, Tables 1 and 2) since NCI-H226 cells constantly showed relative high sub-G1 fractions. Ad-delE1B55 treatments increased hyperploid fractions, more than $4 \mathrm{~N}$ populations, and sub-G1 fractions in MSTO-211H cells, whereas ZOL increased sub-G1 fractions (Fig. 3a, Table 1). A combinatory use of ZOL and Ad-delE1B55 further increased sub-G1 populations in MSTO-211H cells compared with treatments of Ad-delE1B55 or ZOL alone, indicating that combination induced further apoptosis. NCI-H28 cells infected with Ad-delE1B55 showed increased G2/M phase populations and hyperploid fractions greater than Ad-delE1B55-infected MSTO-211H cells, and ZOL treatments in NCI-H28 cells augmented S-phase populations 


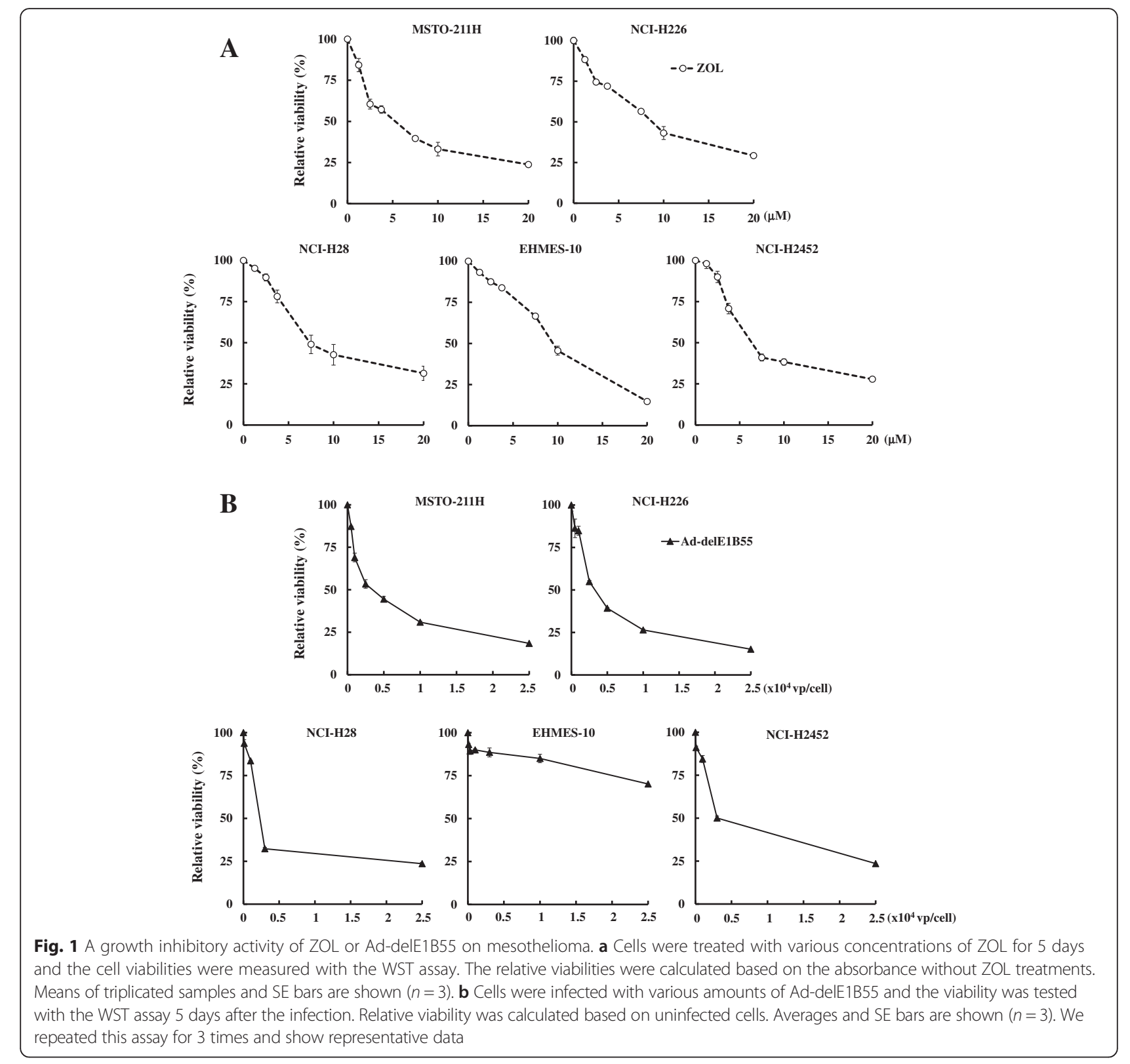

with minimal induction of sub-G1 fractions (Fig. 3b, Table 2). Combination of both agents in NCI-H28 cells increased S-phase and greater than treatments with a single agent, and minimally up-regulated sub-G1 populations. The increased S-phase fraction in NCI-H28 cells may be attributable to failure of Ad-delE1B55-infected cells with the hyperploid fraction to enter into mitosis and consequently the cell cycle were arrested in S-phase and/or G2/ $\mathrm{M}$-phase. We also confirmed the increased S-phase and G2/M-phase in NCI-H28 cells treated with ZOL and AddelE1B55 with western blot analysis (Additional file 3: Figure S3). These cells showed decreased cyclin E and enhanced cyclin $\mathrm{A}$ expression levels, which was compatible with cells in S-phase entry and in a progress from S- to
G2/M-phase. Cells uninfected or infected with Ad-LacZ as a control however showed a minimal level of polyploidy and the sub-G1 fractions did not increase markedly in both MSTO-211H and NCI-H28 cells with Ad-LacZ.

We also examined nuclear configurations of MSTO$211 \mathrm{H}, \mathrm{NCI}-\mathrm{H} 226$ and NCI-H28 cells with Giemsa staining (Fig. 4). These cells treated with ZOL did not show any changed compared untreated cells. In contrast, AddelE1B55 infections increased cells with enlarged and condensed nuclei, which suggested increased nuclear DNA contents and pyknotic changes. Combinatory treatments also showed the same nuclear changes with decreased cell numbers, indicating that cell proliferation was inhibited by the treatments. 


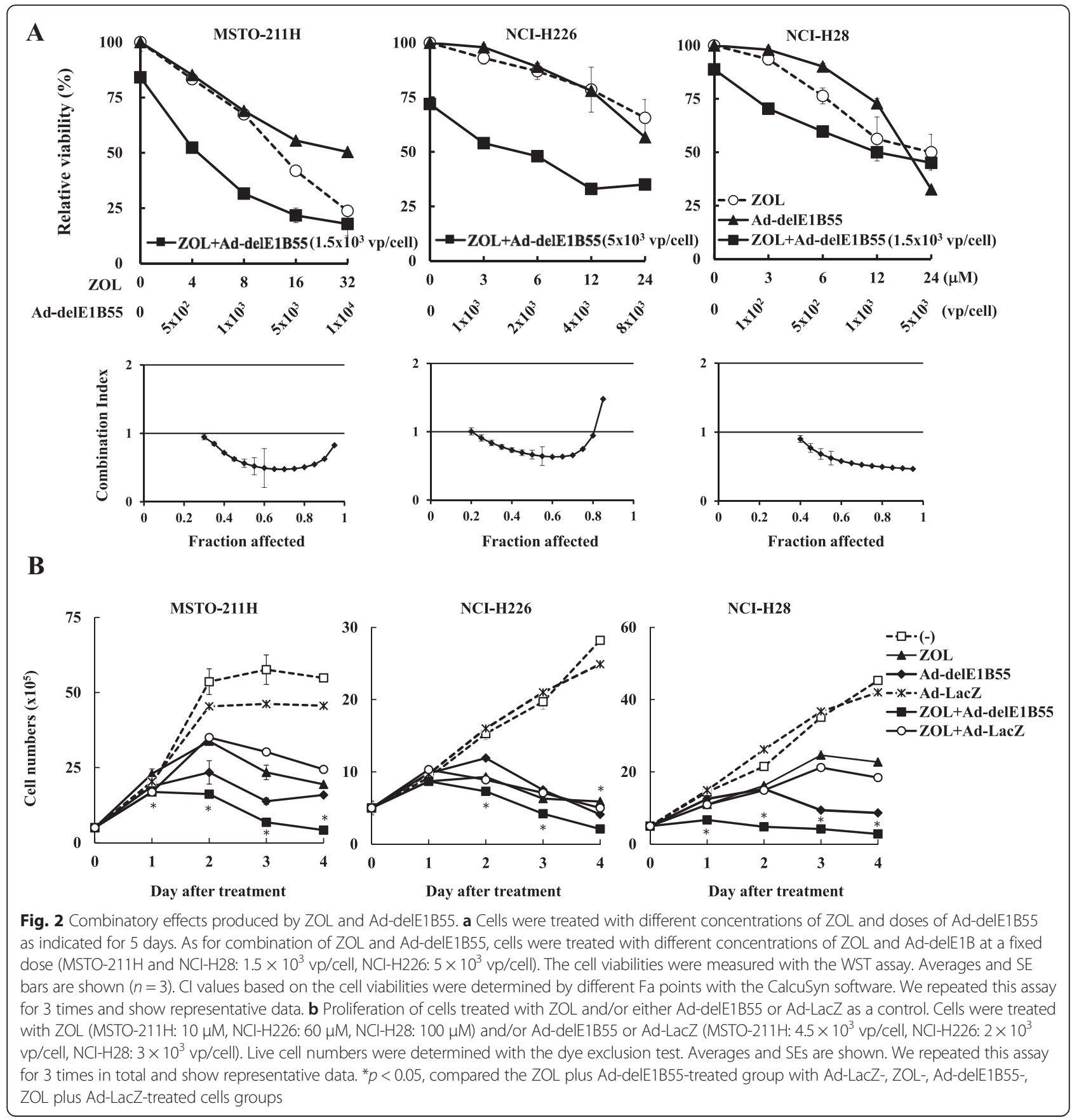

\section{Molecular changes induced by combination of ZOL and Ad-delE1B55}

We examined a possible mechanism of combinatory effects produced by ZOL and Ad-delE1B55 in MSTO$211 \mathrm{H}$ cells with western blot analyses (Fig. 5). E1A became detectable at $24 \mathrm{~h}$ after the infection, but the expression levels were not different from those with additional $10 \mu \mathrm{M}$ of ZOL (Fig. 5a). We also examined a possible involvement of autophagy pathways. Beclin-1 expression levels were down-regulated in cells treated with either Ad-delE1B55 or ZOL at 24 and $48 \mathrm{~h}$, and in Ad-delE1B55-treated cells at 72 and 96 h. Atg5 expression levels in cells treated with Ad-delE1B55 or ZOL minimally decreased at 24 and $48 \mathrm{~h}$ but unchanged after 72 h. Both Beclin-1 and Atg5 expression levels in the combination-treated cells were not different from those in cells treated with a single agent except Beclin-1 expression in Ad-delE1B55-treated cells at $96 \mathrm{~h}$. Moreover, there was no major transition from LC3A/B I to LC3A/ $B$ II accompanied by any treatments including the 


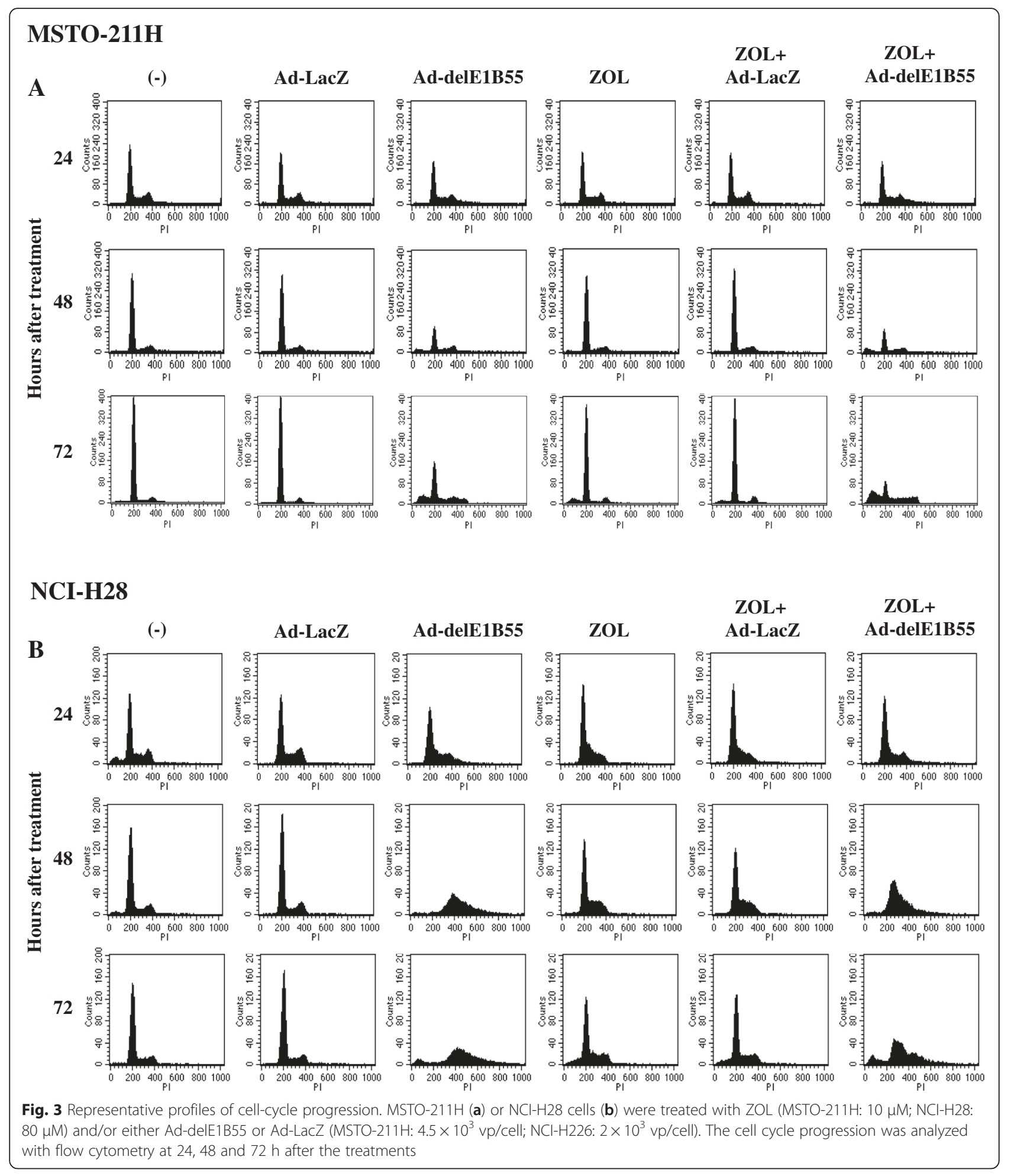

combination although the expression levels of LC3A/B II and to less extent LC3A/B I were enhanced in ZOL-treated cells. In addition, the LC3A/B II expression levels in the combination corresponded to the levels of between AddelE1B55-treated and ZOL-treated cells. Expression levels of Beclin-1, Atg5 and LC3A/B were therefore differentially influenced by the agents. These data collectively indicated that cytotoxicity induced by ZOL might be partly linked with autophagy, but Ad-delE1B- and the combinationinduced cell death were irrelevant to autophagy. 
Table 1 Cell cycle progression of MSTO-211H cells treated with ZOL and/or Ad-delE1B55

\begin{tabular}{|c|c|c|c|c|c|c|}
\hline \multirow[t]{2}{*}{ Time (hrs) } & \multirow[t]{2}{*}{ Treatment } & \multicolumn{5}{|c|}{ Cell cycle distribution $(\% \pm \mathrm{SE})$} \\
\hline & & Sub-G1 & G1 & $S$ & $\mathrm{G} 2 / \mathrm{M}$ & $>4 \mathrm{~N}$ \\
\hline \multirow[t]{6}{*}{24} & $(-)$ & $2.04 \pm 0.04$ & $58.80 \pm 0.20$ & $18.17 \pm 0.24$ & $20.67 \pm 0.31$ & $0.81 \pm 0.06$ \\
\hline & Ad-LacZ & $2.90 \pm 0.16$ & $57.30 \pm 0.19$ & $17.59 \pm 0.22$ & $20.97 \pm 0.26$ & $1.83 \pm 0.04$ \\
\hline & Ad-delE1B55 & $2.61 \pm 0.16$ & $55.29 \pm 0.07$ & $20.41 \pm 0.11$ & $20.08 \pm 0.27$ & $2.22 \pm 0.11$ \\
\hline & ZOL & $2.47 \pm 0.05$ & $57.47 \pm 0.10$ & $18.34 \pm 0.27$ & $20.70 \pm 0.22$ & $1.62 \pm 0.09$ \\
\hline & $\mathrm{ZOL}+\mathrm{Ad}-\mathrm{LacZ}$ & $3.58 \pm 0.17$ & $55.98 \pm 0.16$ & $17.94 \pm 0.17$ & $20.84 \pm 0.10$ & $2.22 \pm 0.08$ \\
\hline & ZOL + Ad-delE1B55 & $3.72 \pm 0.05$ & $53.99 \pm 0.11$ & $20.53 \pm 0.23$ & $19.42 \pm 0.35$ & $3.00 \pm 0.09$ \\
\hline \multirow[t]{6}{*}{48} & $(-)$ & $1.73 \pm 0.07$ & $76.54 \pm 0.12$ & $8.20 \pm 0.03$ & $12.59 \pm 0.08$ & $1.18 \pm 0.04$ \\
\hline & Ad-LacZ & $1.37 \pm 0.08$ & $75.90 \pm 0.38$ & $8.60 \pm 0.16$ & $12.55 \pm 0.33$ & $1.82 \pm 0.03$ \\
\hline & Ad-delE1B55 & $12.25 \pm 0.04$ & $51.87 \pm 0.21$ & $12.47 \pm 0.13$ & $21.56 \pm 0.19$ & $2.32 \pm 0.03$ \\
\hline & $\mathrm{ZOL}$ & $3.82 \pm 0.08$ & $76.77 \pm 0.43$ & $6.70 \pm 0.09$ & $11.31 \pm 0.33$ & $1.60 \pm 0.01$ \\
\hline & $\mathrm{ZOL}+\mathrm{Ad}-\mathrm{LacZ}$ & $2.81 \pm 0.11$ & $76.08 \pm 0.33$ & $7.47 \pm 0.12$ & $11.95 \pm 0.13$ & $1.96 \pm 0.06$ \\
\hline & $\mathrm{ZOL}+\mathrm{Ad}$-delE1B55 & $19.69 \pm 0.18^{a}$ & $47.47 \pm 0.19^{a}$ & $15.42 \pm 0.44^{a}$ & $15.23 \pm 0.35$ & $2.69 \pm 0.16$ \\
\hline \multirow[t]{6}{*}{72} & $(-)$ & $0.96 \pm 0.02$ & $87.55 \pm 0.01$ & $3.77 \pm 0.13$ & $7.26 \pm 0.19$ & $0.59 \pm 0.05$ \\
\hline & Ad-LacZ & $1.46 \pm 0.10$ & $87.58 \pm 0.30$ & $2.75 \pm 0.05$ & $7.79 \pm 0.14$ & $0.51 \pm 0.03$ \\
\hline & Ad-delE1B55 & $22.52 \pm 0.07$ & $43.47 \pm 0.18$ & $11.57 \pm 0.14$ & $12.89 \pm 0.23$ & $10.14 \pm 0.23$ \\
\hline & ZOL & $11.19 \pm 0.08$ & $76.77 \pm 0.28$ & $3.45 \pm 0.08$ & $7.93 \pm 0.20$ & $0.81 \pm 0.12$ \\
\hline & ZOL + Ad-LacZ & $6.44 \pm 0.03$ & $80.27 \pm 0.15$ & $3.04 \pm 0.04$ & $9.66 \pm 0.13$ & $0.78 \pm 0.04$ \\
\hline & ZOL + Ad-delE1B55 & $35.52 \pm 0.05^{\mathrm{a}}$ & $24.06 \pm 0.30^{a}$ & $13.89 \pm 0.13^{b}$ & $11.83 \pm 0.21$ & $15.41 \pm 0.19$ \\
\hline \multirow[t]{6}{*}{96} & $(-)$ & $1.03 \pm 0.07$ & $87.25 \pm 0.01$ & $4.43 \pm 0.03$ & $6.93 \pm 0.06$ & $0.50 \pm 0.03$ \\
\hline & Ad-LacZ & $1.16 \pm 0.06$ & $87.36 \pm 0.28$ & $3.34 \pm 0.17$ & $7.65 \pm 0.11$ & $0.68 \pm 0.04$ \\
\hline & Ad-delE1B55 & $12.14 \pm 0.27$ & $53.92 \pm 0.29$ & $11.93 \pm 0.06$ & $13.21 \pm 0.27$ & $9.32 \pm 0.31$ \\
\hline & ZOL & $9.32 \pm 0.11$ & $80.72 \pm 0.21$ & $3.98 \pm 0.06$ & $5.73 \pm 0.07$ & $0.40 \pm 0.07$ \\
\hline & ZOL + Ad-LacZ & $8.93 \pm 0.17$ & $78.40 \pm 0.17$ & $4.22 \pm 0.14$ & $7.92 \pm 0.13$ & $0.79 \pm 0.04$ \\
\hline & ZOL+ Ad-delE1B55 & $40.75 \pm 0.08^{a}$ & $21.50 \pm 0.21^{\mathrm{a}}$ & $14.26 \pm 0.11^{b}$ & $10.58 \pm 0.12$ & $13.59 \pm 0.18^{b}$ \\
\hline
\end{tabular}

Cells were treated with ZOL $(10 \mu \mathrm{M})$ and/or either Ad-delE1B55 or Ad-LacZ $\left(4.5 \times 10^{3} \mathrm{vp} / \mathrm{cell}\right)$ and cultured for $24-96 \mathrm{~h}$. Cell cycle profiles were analyzed with flow cytometry. Averages with SEs are shown $(n=3)$

${ }^{a} p<0.01,{ }^{b} p<0.05$; compared between ZOL + Ad-delE1B55-treated cells, and Ad-LacZ, ZOL-, Ad-delE1B55-, ZOL + Ad-LacZ-treated cells

We then examined expression levels of apoptosislinked proteins (Fig. 5b). ZOL at $10 \mu \mathrm{M}$ in MSTO-211H cells did not influence p53 or phosphorylated p53 levels, or induce cleavages of caspase- $3,-8$ and PARP, but minimally augmented that of caspase-9. In contrast, AddelE1B55-treated cells augmented p53 and phosphorylated p53 levels, and cleavages of caspase-3,-9 and PARP, but not that of caspase-8. Apoptosis by ZOL or AddelE1B55 could thus be differentially activated through intrinsic or extrinsic pathways. Cells treated with the combination showed up-regulated p53 expression, p53 phosphorylation, and subsequently enhanced cleavage of caspase-3, 8, 9 and PARP at a greater level than those treated with ZOL or Ad-delE1B alone at 24 and $48 \mathrm{~h}$. The up-regulated expression in the combination was however not detected after $72 \mathrm{~h}$ except the cleavage PARP. We noticed that Bid expression was downregulated in the combination at $96 \mathrm{~h}$, but truncated Bid, which contributes to the linkage between the death receptor- and the mitochondria-mediated apoptosis, was not induced. Interestingly, phosphorylated H2AX molecules, a marker of DNA damages, was augmented in Ad-delE1B55- and ZOL-treated cells, suggesting that DNA damages were involved in both type of the cell death. The combination did not increase the phosphorylated H2AX levels greater than the summated levels of Ad-delE1B- and ZOL-treated cases. These data collectively indicated that the combinatory cytotoxicity at an early phase up to $48 \mathrm{~h}$ was at least partly due to augmented p53 levels and activated downstream apoptosis, but activation of the p53 downstream pathways was less significantly attributable to the cytotoxicity at the later phase.

\section{Expression of Ad receptors and Ad infectivity after ZOL treatments}

We examined changes of CAR and integrin $\alpha v \beta 3$ or $\alpha \mathrm{v} \beta 5$ expression levels by ZOL treatments on MSTO- 
Table 2 Cell cycle progression of NCl-H28 cells treated with ZOL and/or Ad-delE1B55

\begin{tabular}{|c|c|c|c|c|c|c|}
\hline \multirow[t]{2}{*}{ Time (hrs) } & \multirow[t]{2}{*}{ Treatment } & \multicolumn{5}{|c|}{ Cell cycle distribution $(\% \pm \mathrm{SE})$} \\
\hline & & Sub-G1 & G1 & S & G2/M & $>4 \mathrm{~N}$ \\
\hline \multirow[t]{6}{*}{24} & $(-)$ & $8.57 \pm 0.34$ & $57.61 \pm 1.07$ & $15.48 \pm 0.53$ & $16.96 \pm 0.89$ & $0.92 \pm 0.21$ \\
\hline & Ad-LacZ & $0.17 \pm 0.02$ & $58.59 \pm 0.71$ & $18.33 \pm 0.19$ & $22.24 \pm 0.39$ & $1.18 \pm 0.17$ \\
\hline & Ad-delE1B55 & $0.25 \pm 0.10$ & $59.35 \pm 0.68$ & $20.28 \pm 0.08$ & $15.33 \pm 0.38$ & $5.45 \pm 0.19$ \\
\hline & $\mathrm{ZOL}$ & $0.16 \pm 0.03$ & $61.76 \pm 0.64$ & $25.71 \pm 0.31$ & $212.15 \pm 0.48$ & $0.89 \pm 0.05$ \\
\hline & $\mathrm{ZOL}+\mathrm{Ad}-\mathrm{LacZ}$ & $0.15 \pm 0.03$ & $67.62 \pm 0.48$ & $21.85 \pm 0.35$ & $9.87 \pm 0.20$ & $0.96 \pm 0.07$ \\
\hline & ZOL + Ad-delE1B55 & $0.23 \pm 0.03$ & $65.45 \pm 0.73$ & $17.33 \pm 0.21$ & $14.21 \pm 0.38$ & $3.24 \pm 0.24$ \\
\hline \multirow[t]{6}{*}{48} & $(-)$ & $2.79 \pm 0.15$ & $75.8 \pm 0.13$ & $9.30 \pm 0.05$ & $13.66 \pm 0.20$ & $0.93 \pm 0.06$ \\
\hline & Ad-LacZ & $0.24 \pm 0.01$ & $73.42 \pm 0.15$ & $9.22 \pm 0.21$ & $16.30 \pm 0.20$ & $1.08 \pm 0.13$ \\
\hline & Ad-delE1B55 & $1.17 \pm 0.05$ & $1.70 \pm 0.22$ & $8.77 \pm 0.22$ & $36.84 \pm 0.12$ & $51.80 \pm 0.28$ \\
\hline & $\mathrm{ZOL}$ & $0.86 \pm 0.10$ & $58.00 \pm 0.54$ & $25.64 \pm 0.15$ & $15.28 \pm 0.27$ & $0.82 \pm 0.11$ \\
\hline & $\mathrm{ZOL}+\mathrm{Ad}-\mathrm{LacZ}$ & $0.70 \pm 0.03$ & $60.80 \pm 0.20$ & $25.40 \pm 0.27$ & $12.92 \pm 0.28$ & $0.77 \pm 0.03$ \\
\hline & $\mathrm{ZOL}+$ Ad-delE1B55 & $1.44 \pm 0.22$ & $19.93 \pm 1.20$ & $47.98 \pm 1.01^{\mathrm{a}}$ & $1.28 \pm 0.32$ & $0.64 \pm 0.37$ \\
\hline \multirow[t]{6}{*}{72} & $(-)$ & $1.06 \pm 0.02$ & $76.33 \pm 0.64$ & $9.26 \pm 0.23$ & $12.68 \pm 0.28$ & $0.92 \pm 0.21$ \\
\hline & Ad-LacZ & $0.51 \pm 0.06$ & $76.20 \pm 0.37$ & $8.68 \pm 0.26$ & $13.50 \pm 0.46$ & $1.41 \pm 0.07$ \\
\hline & Ad-delE1B55 & $6.67 \pm 0.17$ & $2.15 \pm 0.23$ & $5.12 \pm 0.49$ & $27.45 \pm 0.26$ & $59.21 \pm 0.85$ \\
\hline & $\mathrm{ZOL}$ & $5.67 \pm 0.23$ & $59.46 \pm 0.21$ & $19.55 \pm 0.57$ & $14.86 \pm 0.47$ & $1.02 \pm 0.07$ \\
\hline & $\mathrm{ZOL}+\mathrm{Ad}-\mathrm{LacZ}$ & $6.07 \pm 0.13$ & $61.94 \pm 0.30$ & $16.93 \pm 0.16$ & $14.56 \pm 0.12$ & $0.97 \pm 0.11$ \\
\hline & ZOL + Ad-delE1B55 & $8.56 \pm 0.38^{\mathrm{a}}$ & $7.77 \pm 0.84$ & $41.33 \pm 1.20^{\mathrm{a}}$ & $22.49 \pm 0.42$ & $20.77 \pm 0.11$ \\
\hline
\end{tabular}

Cells were treated with ZOL $(80 \mu \mathrm{M})$ and/or either Ad-delE1B55 or Ad-LacZ ( $\left.2 \times 10^{3} \mathrm{vp} / \mathrm{cell}\right)$ and cultured for $24-72 \mathrm{~h}$. Cell cycle profiles were analyzed with flow cytometry. Averages with SEs are shown $(n=3)$

${ }^{a} p<0.01$; compared between ZOL + Ad-delE1B55-treated cells, and Ad-LacZ-, ZOL-, Ad-delE1B55-, ZOL + Ad-LacZ-treated cells

$211 \mathrm{H}$ and NCI-H28 cells (Fig. 6a, Table 3). Influence of ZOL on the expression level, which was shown as mean fluorescent intensity, was calculated by comparing the level of ZOL-treated cells and that of untreated cells as a control (Table 3). ZOL $(10 \mu \mathrm{M})$ scarcely influenced expression levels on MSTO-211H cells, whereas ZOL $(80 \mu \mathrm{M})$ decreased the levels of integrin $\alpha v \beta 3$ and $\alpha v \beta 5$ on NCI-H28 cell. We also examined effects of ZOL at different concentrations with NCI-H28 cells and found that increased doses of $\mathrm{ZOL}$ decreased the expression levels of integrin in particular $\alpha v \beta 5$ (Additional file 4: Table S1). We could not examine ZOL-mediated effects on MSTO-211H cells at the high concentrations since they became dead at these doses.

We then examined Ad infectivity on mesothelioma using Ad-GFP, replication-incompetent type 5 Ad with the same receptor usage as Ad-delE1B55 (Fig. 6b). Fluorescence intensity of GFP on MSTO-211H cells was not significantly different after ZOL treatments $(10 \mu \mathrm{M})$ but that on NCI-H28 cells increased with ZOL $(80 \mu \mathrm{M})$. We also tested the GFP intensity with different ZOL concentrations, and the infectivity to NCI-H28 cells increased in a dose-dependent manner (Additional file 5: Figure S4). These results indicated that ZOL influenced Ad receptor expression and infectivity of Ad-delE1B55, but these Ad receptor expression levels did not directly correlated with Ad infectivity. Nevertheless, the enhanced infectivity suggested a certain role in the combinatory cytotoxicity in NCI-H28 cells.

\section{Effects of ZOL on viral proliferations of Ad-delE1B55}

We examined whether the combinatory effects were associated with increased production of the viral progenies. MSTO-211H and NCI-H28 cells were infected with Ad-delE1B55 and treated with ZOL, and then the cell lysate was tested for the viral titers with the $\mathrm{TCID}_{50}$ method using A549 cells (Fig. 7a). The viral production in MSTO- $211 \mathrm{H}$ cells remained unchanged except ZOLtreated cells at $72 \mathrm{~h}$ which decreased the production. In contrast, ZOL treatments in NCI-H28 cells augmented the viral propagations. Enhanced cytotoxicity by the combination in MSTO- $211 \mathrm{H}$ cells were thereby irrelevant to production of infectious Ad progenies, whereas that in NCI-H28 cells could be attributable to the enhanced production of viral progenies. We also examined expression of E1A, the early gene product, and hexon, one of the late gene product after ZOL treatments (Fig. 7b). E1A expression in MSTO-211H cells remained unchanged or decreased with ZOL treatments, and hexon expression was not markedly different between ZOL-untreated and ZOL-treated cells. In contrast, E1A expression in NCI-H28 cells was initially lower in ZOL- 


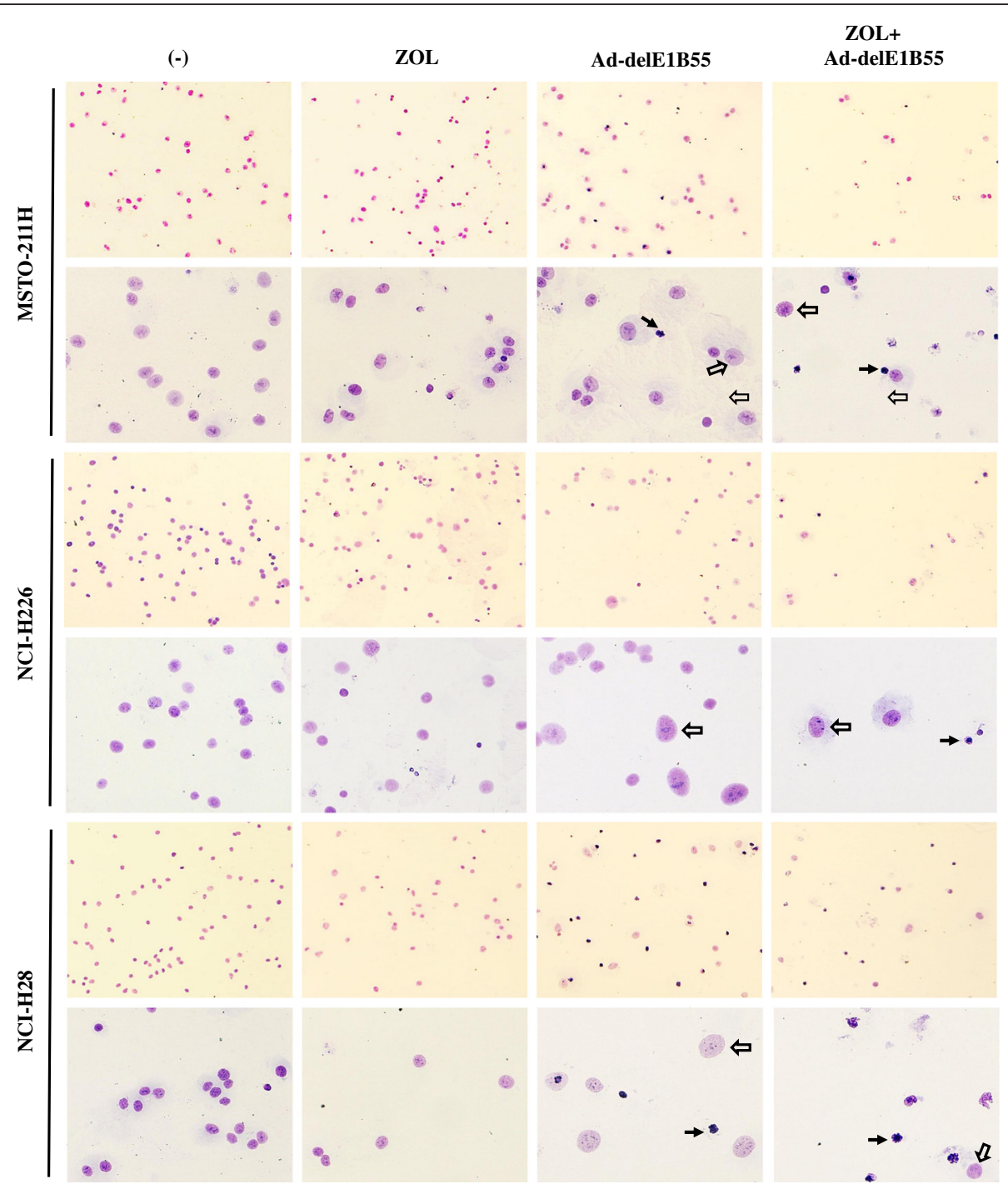

Fig. 4 Giemsa staining after Ad-delE1B55 infection. Cells were treated with ZOL (MSTO-211H: $10 \mu \mathrm{M}, \mathrm{NCl}-\mathrm{H} 226: 60 \mu \mathrm{M}, \mathrm{NCl}-\mathrm{H} 28: 80 \mu \mathrm{M}$ ) and/or Ad-delE1B55 (MSTO-211H: $2 \times 10^{3} \mathrm{vp} / \mathrm{cell}$, NCl-H226: $1 \times 10^{3} \mathrm{vp} / \mathrm{cell}$, NCl-H28: $2 \times 10^{3} \mathrm{vp} /$ cell) for $72 \mathrm{~h}$. Nuclear morphological changes were examined after the Giemsa staining. In Ad-delE1B55-treated cells, small and highly condensed nucleus (solid arrow) and large and uncondensed nucleus (open arrow) were detected. An upper panel and lower panel are x4 and x10 in magnifications, respectively

treated cells at $24 \mathrm{~h}$ than in ZOL-untreated cells, but became greater in ZOL-treated than ZOL-untreated cells at 48 and $72 \mathrm{~h}$. Hexon expression likewise was upregulated by ZOL treatments after $48 \mathrm{~h}$. The E1A and the hexon expression levels in NCI-H28 cells were correlated with production of viral progenies.

\section{Discussion}

In this study, we demonstrated that ZOL and AddelE1B55 induced growth suppression and the combination of both agents produced additive or synergistic inhibitory effects on mesothelioma cells. ZOL and AddelE1B55 induced differential cell cycle changes and the combinatory effects were achieved through enhanced apoptosis or increased viral replication. It is the first report to our knowledge that bisphosphonates and replication-competent Ad produced combinatory effects.

We noticed that MSTO-211H cells were sensitive to ZOL with the dye exclusion test, but NCI-H226 and $\mathrm{NCI}-\mathrm{H} 28$ cells required a relatively high dose to induce cell growth suppression although these 3 kinds of cells were similarly susceptible to ZOL with the WST assay. We then tested MSTO-211H cells with a low ZOL concentration and NCI-H226 and NCI-H28 cells with a high ZOL doses in other experimental conditions. Cell cycle analyses showed that Ad-delE1B55 and ZOL produced differential effects which was characterized by hyperploidy and S-phase arrest. A precise mechanism of hyperploidy and S-phase arrest remain currently unknown, but the present study showed that Ad-infected 

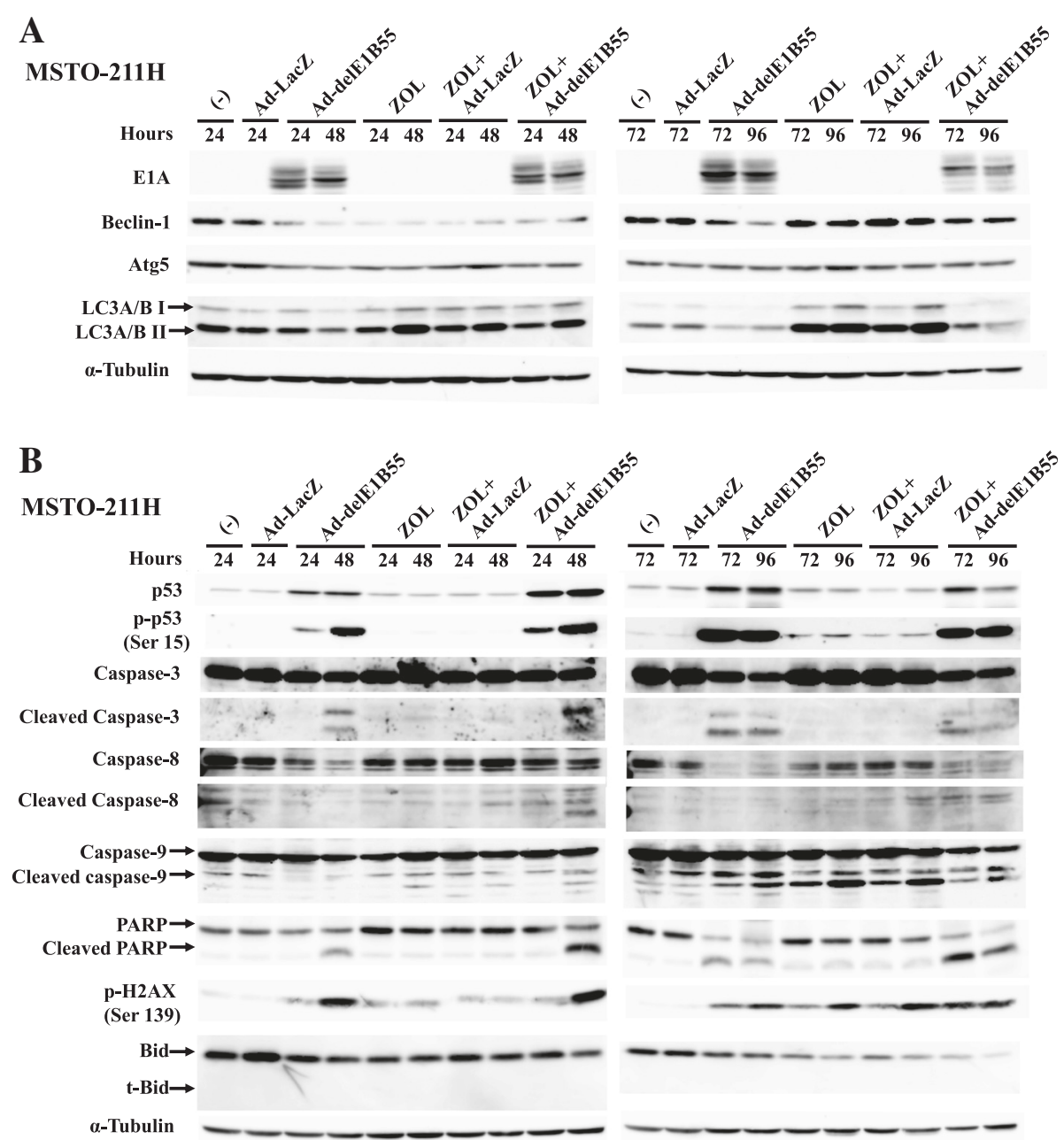

Fig. 5 Expression of molecules linked with cell death. MSTO-211H cells were treated with ZOL $(20 \mu \mathrm{M})$ and Ad-delE1B55 or Ad-LacZ $\left(3 \times 10^{3}\right.$ vp/ cell) as a control. Cells were cultured for the indicated times. Expression of viral proteins and autophagy pathways (a) and molecules linked with cell death pathways (b) were examined with respective Ab and $\mathrm{a}$-Tubulin was used as a loading control

cells induced enlarged nuclei followed by pyknotic configurations, which was compatible with hyperploidy and apoptotic cell death. In addition, augmented cyclin A and decreased cyclin E expression suggested induction of S-phase arrest, and phosphorylation of H2AX indicated activation of a cellular system detecting viral DNA increase. Hyperploidy could be due to a direct or an indirect consequence of accumulated viral DNA and an activated DNA damage sensor system thereafter. Furthermore, increased S-phase populations could be resulted from impaired cell cycle progression at S- and G2-phase and from failure of cells to shift into mitosis. Previous studies in fact reported that ZOL induced Sphase arrest and that the cell cycle changes were subjected to aberrant signals induced by mutated tumor suppressor genes [20].

The majority of human mesothelioma possesses the wild type $p 53$ gene but lacks the $p 14^{A R F}$ and the $16^{I N K 4 A}$ genes, which subsequently leads to loss of the p53 functions and activation of the $\mathrm{pRb}$ pathways, respectively. ZOL activated endogenous p53 downstream pathways on mesothelioma even though the cell death did not depend on the p53 pathways in our recent study [10]. Nevertheless, up-regulated p53 levels increased sensitivity to cisplatin, one of the first-line chemotherapeutic agents for mesothelioma [11]. Consequently, ZOL facilitated DNA damage responses through the activated p53 downstream pathways despite p53 independence of ZOL-mediated cytotoxicity. On the other hand, AddelE1B55 also augmented endogenous p53 levels and subsequently activated the p53 functions in p53 wildtype mesothelioma, which was evidenced by p53 phosphorylation, $\mathrm{pRb}$ dephosphorylation and cleavage of caspases [17]. The present study showed that combination of ZOL and Ad-delE1B55 increased phosphorylated p53 and cleaved caspase-3 and we therefore 
A
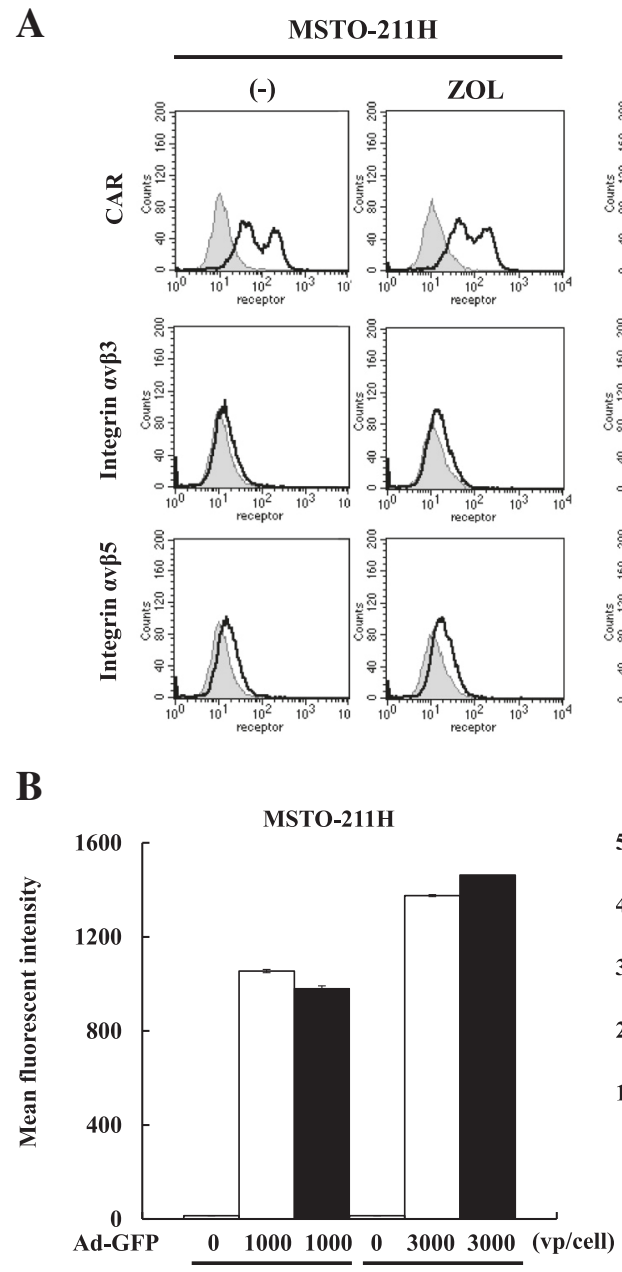
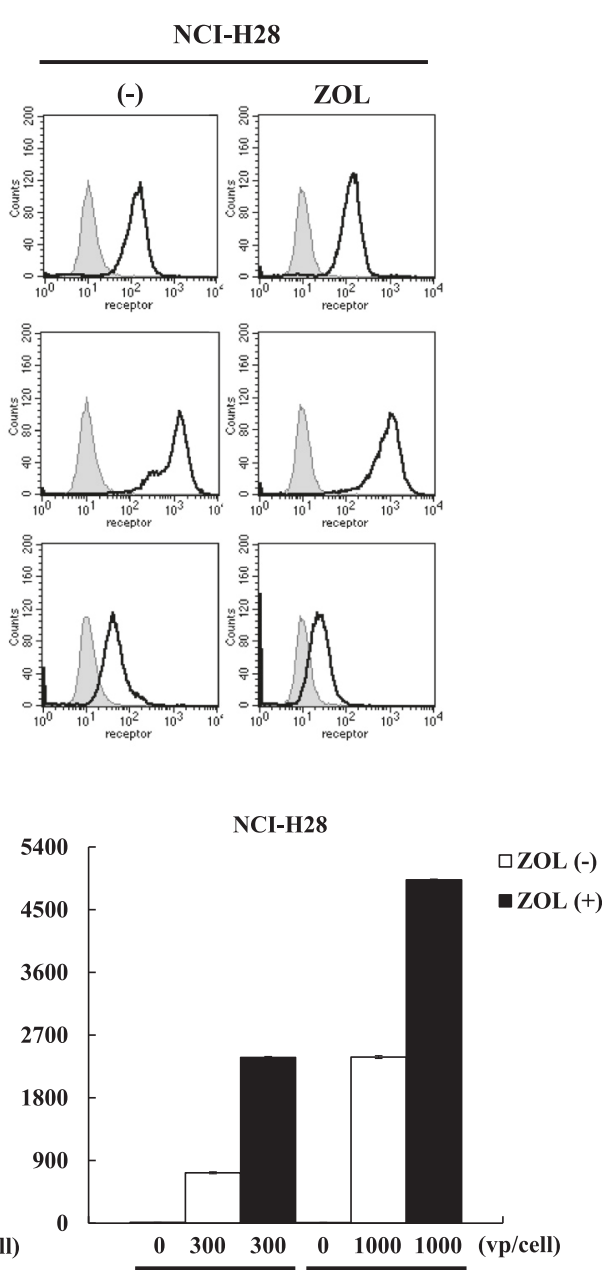

Fig. 6 Expression of Ad receptors and infectivity of Ad. a Expression levels of CAR and integrin av $\beta 3$ or av 35 molecules on MSTO-211H and NCI-H28 cells were analyzed with flow cytometry. Representative profiles of cells untreated or treated with ZOL (MSTO-211H: $10 \mu \mathrm{M}, \mathrm{NCl}-\mathrm{H} 28: 80 \mu \mathrm{M})$ for $48 \mathrm{~h}$ are shown. CAR expression on MSTO-211H cells was always biphasic and both low and high CAR-positive cells were detected Shaded profiles are those stained with 2nd Ab alone. b Efficacy of Ad infection examined with Ad-GFP. Cells were infected with Ad-GFP (300-3,000 vp/cell) and treated with or without ZOL (MSTO-211H: $10 \mu \mathrm{M}, \mathrm{NCl}-\mathrm{H} 28: 80 \mu \mathrm{M}$ ) for $48 \mathrm{~h}$. The mean fluorescent intensity of the GFP-positive cells was analyzed with flow cytometry and expressed with an arbitrary unit. Averages and the SE bars are shown $(n=3)$

presume it rational to use the agent together from the viewpoint of activation of the p53 pathways. Moreover, effects of ZOL on Ad replication also needs to be clarified since viral replication itself induced cytotoxicity to the infected cells.

The ZOL inhibits prenylation of small $G$ proteins and consequently suppresses functions of small $G$ proteins $[5,8-10]$. On the other hand, mesothelioma is often defective of the Hippo pathways due to mutation of the NF/Merlin gene [21, 22]. Loss of NF/Merlin functions leads to dysregulation of multiple signal pathways, and up-regulated functions of small $\mathrm{G}$ proteins is one of the uncontrolled regulation. Ras and RhoA family proteins, one of the major small $G$ proteins, are in fact activated in malignant mesothelioma and subsequently mitogenactivated protein kinases are also activated in most of the mesothelioma cells [10, 23]. ZOL thereby blocks one of the dysfunctional Hippo pathways and combinatory effects of ZOL and Ad-delE1B55 can inhibit a possible cross-talk between NF/Merlin and the p53 pathways in mesothelioma with deletion of both INK4A/ARF and $\mathrm{NF} /$ Merlin regions.

We examined influence of ZOL on receptor expression levels and infectivity of Ad. Expression levels of major Ad receptors, CAR and integrin $\alpha v \beta 3$ and $\alpha v \beta 5$, were not affected by ZOL on MSTO- $211 \mathrm{H}$ cells, whereas those of integrin but not CAR was downregulated in NCI-H28 cells after ZOL treatments. The differential influence on integrin expression between the tested cells were not due to ZOL concentrations since ZOL at $10 \mu \mathrm{M}$ also decreased integrin levels on NCI$\mathrm{H} 28$ cells. Interestingly, Ad infectivity in NCI-H28 cells 
Table 3 Expression of Ad receptor molecules after ZOL treatments

\begin{tabular}{|c|c|c|c|c|}
\hline Cells & $\mathrm{Ab}$ & ZOL treatment & Mean fluorescent intensity (average \pm SE) & $\%$ radio (average $\pm \mathrm{SE}$ ) \\
\hline \multirow[t]{8}{*}{ MSTO-211H } & \multirow[t]{2}{*}{ 2nd Ab alone } & $(-)$ & $12.42 \pm 0.07$ & \\
\hline & & $(+)$ & $13.44 \pm 0.07$ & $108.19 \pm 0.51$ \\
\hline & \multirow[t]{2}{*}{ CAR } & $(-)$ & $95.21 \pm 2.04$ & \\
\hline & & $(+)$ & $95.86 \pm 0.09$ & $100.69 \pm 0.09$ \\
\hline & \multirow[t]{2}{*}{ Integrin av $\beta 3$} & $(-)$ & $13.59 \pm 0.02$ & \\
\hline & & $(+)$ & $14.67 \pm 0.04$ & $107.92 \pm 0.04$ \\
\hline & \multirow[t]{2}{*}{ Integrin av $\beta 5$} & $(-)$ & $15.64 \pm 0.10$ & \\
\hline & & $(+)$ & $18.12 \pm 0.03$ & $115.88 \pm 0.64$ \\
\hline \multirow[t]{8}{*}{$\mathrm{NCl}-\mathrm{H} 28$} & \multirow[t]{2}{*}{ 2nd $\mathrm{Ab}$ alone } & $(-)$ & $11.39 \pm 0.03$ & \\
\hline & & $(+)$ & $11.55 \pm 0.86$ & $101.38 \pm 0.79$ \\
\hline & \multirow[t]{2}{*}{ CAR } & $(-)$ & $127.26 \pm 0.31$ & \\
\hline & & $(+)$ & $119.29 \pm 0.69$ & $93.73 \pm 0.03$ \\
\hline & \multirow[t]{2}{*}{ Integrin av $\beta 3$} & $(-)$ & $1006.61 \pm 1.24$ & \\
\hline & & $(+)$ & $718.29 \pm 2.33$ & $71.36 \pm 0.12$ \\
\hline & \multirow[t]{2}{*}{ Integrin av $\beta 5$} & $(-)$ & $44.01 \pm 0.09$ & \\
\hline & & $(+)$ & $22.01 \pm 0.03$ & $50.01 \pm 0.13$ \\
\hline
\end{tabular}

Cells untreated or treated with ZOL (MSTO-211H: $10 \mu \mathrm{M}, \mathrm{NCl}-\mathrm{H} 28: 80 \mu \mathrm{M})$ for $48 \mathrm{~h}$ were subjected to flow cytometry to detect expression of the cellular receptors of type $5 \mathrm{Ad}$. Means fluorescence intensity was expressed as an arbitrary unit and influence of ZOL on the expression levels was expressed as a percent ratio based on respective ZOL-untreated cases as a control $(n=3)$

was rather enhanced after ZOL treatments despite the down-regulated integrin expression, indicating that the integrin as well as CAR did not play a crucial role in the infection in NCI-H28 cells. ZOL treatments induced alteration of actin fiber structures followed by morphological changes since small $G$ proteins in particular Rho family proteins played a role in the organization of actin fibers in mesothelioma [24]. Moreover, a previous study reported that ZOL specifically suppressed integrin $\alpha v \beta 3$ but not $\alpha 5 \beta 1$ expression through down-regulate focal adhesion kinase [25]. On the other hand, suppressed $\alpha v \beta 5$ expression, demonstrated in the present study, had not yet been reported. Down-regulated expression of integrin molecules and enhanced Ad infectivity can be in part attributable to the ZOL-mediated morphological changes, but inhibition of small $\mathrm{G}$ proteins also influences several intracellular signal pathways and may augment infectivity, for example, due to facilitated viral release into cytoplasm after binding to the cellular receptors. Ad endocytosis via integrin molecules in fact requires activation of the lipid kinase phosphatidylinositol-3-OH kinase, which in turn augments signaling cascades of both Ras and Rho families [26]. In addition, RhoA, Cdc42 and Rab6 were targets for ZOL-induced actions including cell death, cell cycle arrest and modification of actin fiber structure [24]. These reports collectively suggested that combinatory cytotoxicity of ZOL and Ad-delE1B55 was linked with suppressed small $\mathrm{G}$ proteins functions. We also presume that increase infectivity could directly contribute to the enhanced production of Ad progenies since ZOL-treated MSTO-211H cells did not show the increased production but ZOL treatments augmented the production in NCI- $211 \mathrm{H}$ cells. In addition, cells infected with Ad-delE1B55 during the G1 phase of cell cycle exhibited a reduced rate of viral late protein synthesis, and produced fewer viral progenies than cells infected during the S-phase [27]. Cell cycle arrest at S-phase that was observed in ZOL-treated NCI-H28 cells can therefore be favorable for enhanced viral progeny production.

We hypothesized a possible mechanism involved in the combinatory effects. ZOL increased an expression level of p53 in MSTO- $211 \mathrm{H}$ cells, which was induced by AddelE1B55 at $48 \mathrm{~h}$ after the infection, and subsequently activated apoptotic signal pathways which was evidenced by up-regulated cleavages of caspase- $8,-9$ and -3 , and PARP even without Bid truncation. Moreover, the combination markedly increased sub-G1 populations in MSTO-211H cells but ZOL did not influence progeny production of Ad-delE1B55. These data indicated that the combinatory effects in MSTO-211H cells were attributable to ZOLmediated augmented p53 downstream pathways. In contrast, ZOL in NCI-H28 cells augmented the viral infection and the replication, which was also evidenced by elevated or prolonged expression of E1A and subsequent hexon expression. A possible mechanism of the up-regulated Ad infection can be linked with inhibited functions of small G proteins, and the augmented infection was dependent on cells. We noticed ZOL-mediated actions were different among mesothelioma [10, 20] and the present study showed a differential pattern of cell cycle progression and 


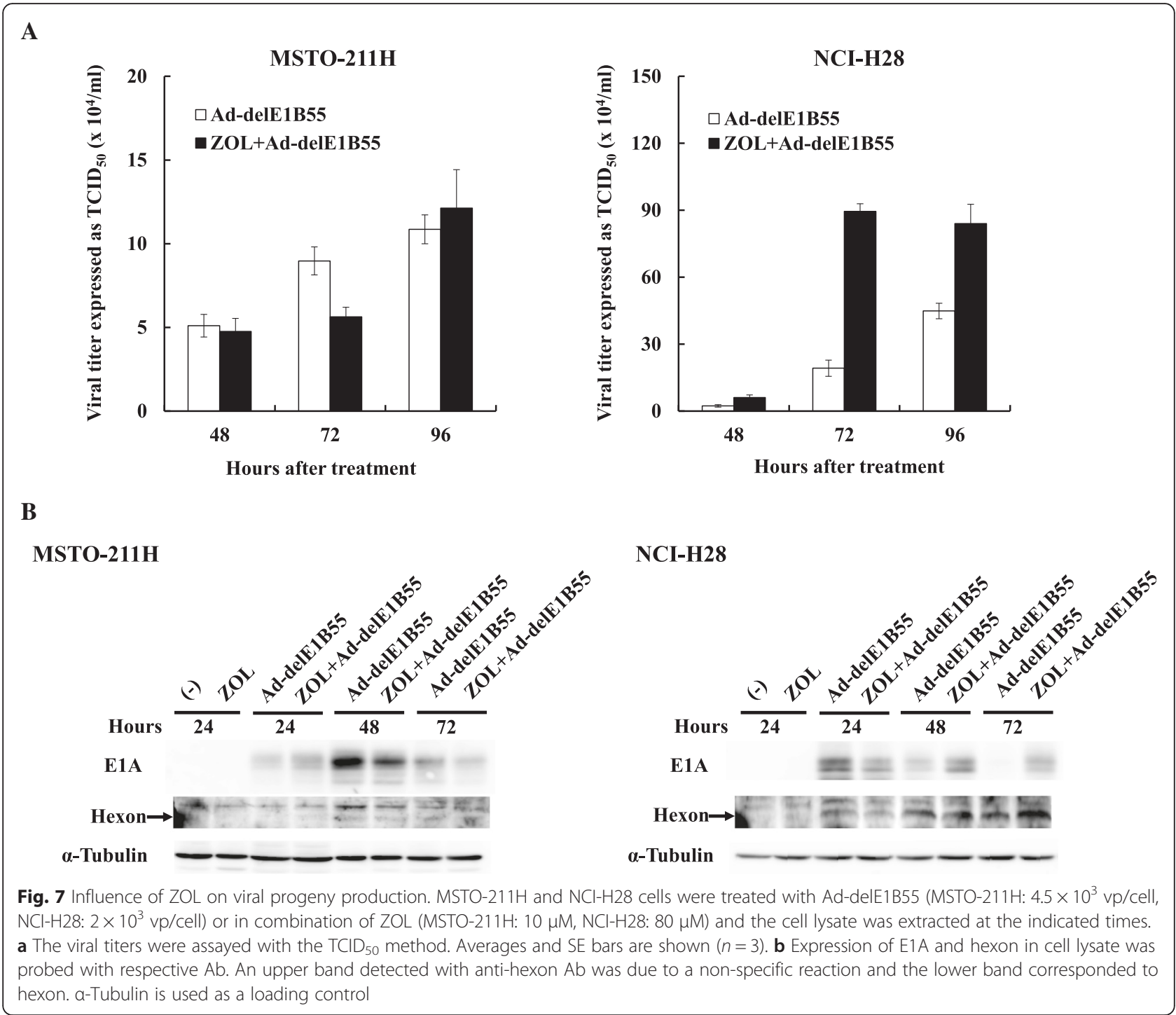

varied expression levels of cell surface molecules between MSTO-211H and NCI-28 cells. These differences are probably resulted from divergent effects of small G proteins in cellular functions among the cells tested.

Ad-delE1B55 has been approved in China as an anticancer agent for head and neck cancer [28] and ZOL is used in a clinical setting in many countries. We has also started a phase I clinical trial with an intrapleural injection of ZOL for mesothelioma patients, which can maintains a local concentration of ZOL to achieve cytotoxicity [29]. The present results under these circumstances will be one of the preclinical or relevant studies for a future clinical trial with replication-competent Ad and an inhibitor for small G proteins.

\section{Conclusions}

In this study, we demonstrated that ZOL and Ad-delE1B55 induced growth arrest and produced combinatory cytotoxic effects on $p 53$ wild-type mesothelioma. We also showed that the combination of ZOL and Ad-delE1B55 produced anti-tumor effects through enhanced apoptotic pathways and up-regulated viral replication. These data collectively suggest a possible cross-talk of small G proteins and Ad replication-induced cell death in mesothelioma.

\section{Additional files}

Additional file 1: Figure S1. Genetic deletion or loss of expression of the $p 14$ and $p 16$ genes in mesothelioma. (A) Polymerase chain reactions to detect the INK4A/ARF region, encoding the p14 and p16 genes. The p14 gene is comprised by exon $1 \beta, 2$ and 3 , and the $p 16$ is exon $1 a, 2$ and 3. NCl-H28, EHMES-10 and NCl-H2452 cells were defective of the p14 and $p 16$ genes. (B) Reverse transcription-polymerase chain reactions to detect the $p 14$ and the $p 16$ transcripts with primers that amplified between exon $1 \beta$ and 2 (for the $p 14$ ) and exon $1 \alpha$ and 2 (for the $p 16$ ). Met-5A cells and GAPDH (glyceraldehyde-3-phosphate dehydrogenase) were used for a positive and a loading control, respectively. MSTO-211 H and $\mathrm{NCl}-\mathrm{H} 226$ cells were negative for the $p 14$ and the p16 transcripts. (PPTX $46 \mathrm{~kb}$ ) 
Additional file 2: Figure S2. Gate control for data collection to remove doublet signals in flow cytometry. Cell cycle profiles of untreated cells were collected with flow cytometry and we set up a gate to collect the data in FL2-width (FL2-W) and FL2-area (FL-2A) (shown in a rectangle) and removed cell doublets in the collection processes. (PPTX $70 \mathrm{~kb}$ )

Additional file 3: Figure S3. Expression of cyclin E and cyclin A. NCl-H28 cells treated with ZOL $(80 \mu \mathrm{M})$ and/or either Ad-delE1B55 or Ad-LacZ $(2 \times$ $10^{3} \mathrm{vp} / \mathrm{cell}$ ) for $48 \mathrm{~h}$ were subjected to western blot analysis. Cyclin $\mathrm{E}$ and $\mathrm{A}$ expression were probed with respective $\mathrm{Ab}$ and $\mathrm{a}$-Tubulin was used as a loading control. (PPTX $84 \mathrm{~kb}$ )

Additional file 4: Table S1. Expression Ad receptor molecules after ZOL treatments on NCl-H28 cells. (DOCX $21 \mathrm{~kb}$ )

Additional file 5: Figure S4. Influence of ZOL on Ad infectivity. $\mathrm{NCl}-\mathrm{H} 28$ cells were infected with Ad-GFP (300 or 1,000 vp/cell) and were treated with ZOL as indicated for $48 \mathrm{~h}$. The mean fluorescent intensity of the GFP-positive cells was analyzed with flow cytometry and expressed with an arbitrary unit. Averages and the SE bars are shown $(n=3)$. Data of ZOL at $80 \mu \mathrm{M}$ are the same as those in Fig. 6b. (PPTX $46 \mathrm{~kb}$ )

\section{Abbreviations}

Ab, antibody; Ad, adenoviruses; Ad-delE1B55, Ad lacking the E1B-55 kDa molecules; CAR, coxsackie adenovirus receptor; $\mathrm{Cl}$, combination index; $\mathrm{Fa}$, fractions affected; GFP, green fluorescent protein; H2AX, H2A histone family member X; LacZ, ß-galactosidase; PARP, poly (ADP-ribose) polymerase; small G proteins, small guanine-nucleotide-binding regulatory proteins; $\mathrm{TCID}_{50}$ median tissue culture infectious dose; vp, virus particles; ZOL, zoledronic acid

\section{Funding}

This study was supported by Grants-in-Aid from Japan Society for the Promotion of Science (JSPS KAKENHI Grant number: 26461183, 26462000), the Grant-in-Aid for Research on seeds for Publicly Essential Drugs and Medical Devices from the Ministry of Health, Labor and Welfare of Japan, and a Grantin-aid from the Nichias Corporation.

\section{Availability of data and materials}

The datasets supporting the conclusion of this article are included within the article and its additional files.

\section{Authors' contributions}

YJ, BZ, KK, TM, MS, and YT designed experimental protocols, prepared materials and conducted experiments. YJ and $\mathrm{HS}$ analyzed the relevant data and prepared the figures. IS, KT, KH and MT organized the experiments and examined the results. MT and YJ prepared the manuscript. All authors read and approved the final manuscript.

\section{Competing interests}

The authors declare that they have no competing interests.

\section{Consent for publication}

Not applicable.

\section{Ethical approval of animal experiments}

This article does not contain any studies with animals performed by any of the authors.

\section{Ethical approval of human specimens}

This article does not contain any studies dealing with human specimens but contains studies with cell lines in vitro. EHMES-10 cells were established from a Japanese patient (deceased) in the Ehime University, Japan, and detailed properties of the cells have been published [18]. The cell line was provided by the original establisher and an ethical approval is not required for the use.

\section{Author details}

'Division of Pathology and Cell Therapy, Chiba Cancer Center Research Institute, 666-2 Nitona, Chuo-ku, Chiba 260-8717, Japan. ²Department of Molecular Biology and Oncology, Graduate School of Medicine, Chiba University, Chiba, Japan. ${ }^{3}$ Division of Respirology, Chiba Cancer Center, Chiba, Japan. ${ }^{4}$ Department of Medical Oncology, Faculty of Medicine, University of Tsukuba, Tsukuba, Japan. ${ }^{5}$ Department of Respirology, Graduate School of
Medicine, Chiba University, Chiba, Japan. ${ }^{6}$ Department of Surgery, School of Medicine, Toho University, Tokyo, Japan. 'Department of Pathology, Tokyo Women's Medical University Yachiyo Medical Center, Yachiyo, Japan.

Received: 16 December 2015 Accepted: 4 July 2016

Published online: 12 July 2016

\section{References}

1. Favoni RE, Florio T. Combined chemotherapy with cytotoxic and targeted compounds for the management of human malignant pleural mesothelioma. Trends Pharmacol Sci. 2011:32(8):463-79.

2. Carbone M, Kratzke RA, Testa JR. The pathogenesis of mesothelioma. Semin Oncol. 2002;29(1):2-17.

3. Lee AY, Raz DJ, He B, Jablons DM. Update on the molecular biology of malignant mesothelioma. Cancer. 2007;109(8):1454-61.

4. Tagawa M, Tada Y, Shimada H, Hiroshima K. Gene therapy for malignant mesothelioma: Current prospects and challenges. Cancer Gene Ther. 2013; 20(3):150-6.

5. Yuasa T, Kimura S, Ashihara E, Habuchi T, Maekawa T. Zoledronic acid: a multiplicity of anti-cancer action. Curr Med Chem. 2007:14(20):2126-35.

6. Lee MV, Fong EM, Singer FR, Guenette RS. Bisphosphonate treatment inhibits the growth of prostate cancer cells. Cancer Res. 2001;61(6):2602-8.

7. Senaratne SG, Pirianov G, Mansi JL, Arnett TR, Colston KW. Bisphosphonates induce apoptosis in human breast cancer cell lines. Br J Cancer. 2000; 82(8):1459-68.

8. Green JR. Bisphosphonates: preclinical review. Oncologist. 2004;9 Suppl 4:3-13.

9. Jones RM, Morgan C, Bertelli G. Effects of zoledronic acid and docetaxel on small GTP-binding proteins in prostate cancer. Tumor Biol. 2015;36(6):4861-9.

10. Okamoto S, Kawamura K, Li Q, Yamanaka M, Yang S, Fukamachi T, Tada Y, Tatsumi K, Shimada H, Hiroshima K, Kobayashi H, Tagawa M. Zoledronic acid produces antitumor effects on mesothelioma through apoptosis and S-phase arrest in p53-independent and Ras prenylation-independent manners. J Thorac Oncol. 2012;7(5):873-82.

11. Okamoto S, Jiang Y, Kawamura K, Shingyoji M, Fukamachi T, Tada Y, Takiguchi Y, Tatsumi K, Shimada H, Hiroshima K, Kobayashi H, Tagawa M. Zoledronic acid produces combinatory anti-tumor effects with cisplatin on mesothelioma by increasing p53 expression levels. PLoS One. 2013;8(3):e60297.

12. Yang CT, You L, Uematsu K, Yeh CC, McCormick F, Jablons DM. p14(ARF) modulates the cytolytic effect of ONYX-015 in mesothelioma cells with wild-type p53. Cancer Res. 2001;61(16):5959-63.

13. Yang S, Kawamura K, Okamoto S, Yamauchi S, Shingyoji M, Sekine I, Kobayashi H, Tada Y, Tatsumi K, Hiroshima K, Shimad H, Tagawa, M. Cytotoxic effects of replication-competent adenoviruses on human esophageal carcinoma are enhanced by forced p53 expression. BMC Cancer. 2015;15:464.

14. Bischoff JR, Kirn DH, Williams A, Heise C, Horn S, Muna M, Ng L, Nye JA, Sampson-Johannes A, Fattaey A, McCormick F. An adenovirus mutant that replicates selectively in p53-deficient human tumor cells. Science. 1996; 274(5286):373-6.

15. Soria C, Estermann FE, Espantman KC, O'Shea CC. Heterochromatin silencing of p53 target genes by a small viral protein. Nature. 2010;466(7310):1076-81.

16. Rothmann T, Hengstermann A, Whitaker NJ, Scheffner M, zur Hausen $H$. Replication of ONYX-015, a potential anticancer adenovirus, is independent of p53 status in tumor cells. J Virol. 1998;72(12):9470-8.

17. Yamanaka M, Tada Y, Kawamura K, Li Q, Okamoto S, Chai K, Yokoi S, Liang M, Fukamachi T, Kobayashi H, Yamaguchi N, Kitamura A, Shimada H, Hiroshima K, Takiguchi Y, Tatsumi K, Tagawa M. E1B-55 kDa-defective adenoviruses activate p53 in mesothelioma and enhance cytotoxicity of anticancer agents. J Thorac Oncol. 2012;7(12):1850-7.

18. Nakataki E, Yano S, Matsumori Y, Goto H, Kakiuchi S, Muguruma H, Bando $Y$, Uehara H, Hamada H, Kito K, Yokoyama A, Sone S. Novel orthotopic implantation model of human malignant pleural mesothelioma (EHMES-10 cells) highly expressing vascular endothelial growth factor and its receptor. Cancer Sci. 2006;97(3):183-91.

19. Di Marzo D, Forte IM, Indovina P, Di Gennaro E, Rizzo V, Giorgi F, Mattioli E, lannuzzi CA, Budillon A, Giordano A, Pentimalli F. Pharmacological targeting of p53 through RITA is an effective antitumoral strategy for malignant pleural mesothelioma. Cell Cycle. 2014;13(4):652-65.

20. Ory B, Blanchard F, Battaglia S, Gouin F, Rédini F, Heymann D. Zoledronic acid activates the DNA S-phase checkpoint and induces osteosarcoma cell death characterized by apoptosis-inducing factor and endonuclease-G 
translocation independently of p53 and retinoblastoma status. Mol Pharmacol. 2007;71(1):333-43.

21. Sekido Y. Molecular pathogenesis of malignant mesothelioma. Carcinogenesis. 2013:34(7):1413-9.

22. Moroishi T, Hansen CG, Guan KL. The emerging roles of YAP and TAZ in cancer. Nat Rev Cancer. 2015;15(2):73-9.

23. Patel MR, Jacobson BA, De A, Frizelle SP, Janne P, Thumma SC, Whitson BA, Farassati F, Kratzke RA. Ras pathway activation in malignant mesothelioma. J Thorac Oncol. 2007;2(9):789-95.

24. Okamoto S, Jiang Y, Kawamura K, Shingyoji M, Tada Y, Sekine I, Takiguchi Y, Tatsumi K, Kobayashi H, Shimada H, Hiroshima K, Tagawa M. Zoledronic acid induces apoptosis and S-phase arrest in mesothelioma through inhibiting Rab family proteins and topoisomerase II actions. Cell Death Dis. 2014;5:e1517.

25. Bezzi M, Hasmim M, Bieler G, Dormond O, Rüegg C. Zoledronate sensitizes endothelial cells to tumor necrosis factor-induced programmed cell death: evidence for the suppression of sustained activation of focal adhesion kinase and protein kinase B/Akt. J Biol Chem. 2003;278(44):43603-14.

26. Li E, Stupack D, Bokoch GM, Nemerow GR. Adenovirus endocytosis requires actin cytoskeleton reorganization mediated by Rho family GTPases. J Virol. 1998;72(11):8806-12.

27. Goodrum FD, Ornelles DA. The early region 1B 55-kilodalton oncoprotein of adenovirus relieves growth restrictions imposed on viral replication by the cell cycle. J Virol. 1997;71(1):548-61.

28. Ma G, Shimada H, Hiroshima K, Tada Y, Suzuki N, Tagawa M. Gene medicine for cancer treatment: Commercially available medicine and accumulated clinical data in China. Drug Des Dev Ther. 2008:2:115-22.

29. Tada Y, Hiroshima K, Shimada H, Shingyoji M, Suzuki T, Umezawa H, Sekine I, Takiguchi Y, Tatsumi K, Tagawa, M. An intrapleural administration of zoledronic acid for inoperable malignant mesothelioma patients: A phase I clinical study protocol. SpringerPlus. 2016;5:195.

\section{Submit your next manuscript to BioMed Central and we will help you at every step:}

- We accept pre-submission inquiries

- Our selector tool helps you to find the most relevant journal

- We provide round the clock customer support

- Convenient online submission

- Thorough peer review

- Inclusion in PubMed and all major indexing services

- Maximum visibility for your research

Submit your manuscript at www.biomedcentral.com/submit

C Biomed Central 